\title{
Limits of conservation agriculture to overcome low crop yields in sub-Saharan Africa
}

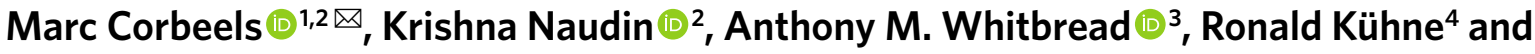 \\ Philippe Letourmy²
}

Conservation agriculture (CA) has become a dominant paradigm in scientific and policy thinking about the sustainable intensification of food production in sub-Saharan Africa. Yet claims that CA leads to increasing crop yields in African smallholder farming systems remain controversial. Through a meta-analysis of 933 observations from 16 different countries in sub-Saharan African studies, we show that average yields under CA are only slightly higher than those of conventional tillage systems (3.7\% for six major crop species and $\mathbf{4 . 0 \%}$ for maize). Larger yield responses for maize result from mulching and crop rotations/intercropping. When CA principles are implemented concomitantly, maize yield increases by $\mathbf{8 . 4 \%}$. The largest yield benefits from CA occur in combination with low rainfall and herbicides. We conclude that although CA may bring soil conservation benefits, it is not a technology for African smallholder farmers to overcome low crop productivity and food insecurity in the short term.

espite its large agricultural potential ${ }^{1}$, sub-Saharan Africa is at high food security risk. The combination of a growing population and continued economic growth is projected to triple the demand for food by 2050, while expenditures on food imports are already high ${ }^{2}$. To meet this rising demand, food systems should increase production while improving resource-use efficiency and environmental performance to ensure their sustainability. Sustainable intensification of crop production-that is, increasing production from existing cropland in ways that have lower environmental impacts and do not undermine our capacity to continue producing food in the future ${ }^{3}-$ is seen as key to food systems achieving these goals ${ }^{4}$.

Conservation agriculture (CA) is widely proposed as one of the promising pathways to the sustainable intensification of food production $^{5,6}$. The practice of CA is based on three crop management principles: direct seeding of crops with minimal soil disturbance (no/reduced tillage, RT); retention of crop residues as mulch on the soil surface (M); and adoption of crop rotations and/or intercropping (IR). Originally, CA was advocated for its potential to conserve soil and water and to enhance soil fertility by reducing soil erosion, soil organic matter loss and soil structural breakdown $n^{5,7}$. More recently, however, CA has been reframed as a technology for increasing crop yields that is able to ensure the food security of smallholder farmers-especially in the African context ${ }^{8}$.

Today, many local and international agricultural development agencies, donors and governments, including the Food and Agriculture Organization of the United Nations (FAO), strongly advocate CA as a strategy to overcome the low crop productivity and poor profitability of smallholder farms in sub-Saharan Africa. Conservation agriculture is also the object of government policies in several countries of Eastern and Southern Africa. Such strong support for CA has incited a critical debate among researchers over the claims that CA increases crop yields on smallholder farms in sub-Saharan Africa ${ }^{9-13}$.
The existing literature is scattered and not always consistent. A recent effort to fill this knowledge gap-a global meta-analysis ${ }^{14}$ with $70 \%$ of primary data points from North America and Europehas offered limited insight into the African context. In recent years, a growing number of studies comparing the crop yields in CA and conventional tillage-based (CT) experimental treatments have been carried out in sub-Saharan Africa. These studies have been conducted under a range of conditions (climate, soil, management, cropping systems). The fact that CA is not a single-component technology but rather based on three principles means that the effects on crop yield are often complex. Moreover, the operationalization of CA principles can vary substantially across agro-environments ${ }^{15,16}$, meaning that the specific management components of a CA system (seeding method, fertilization, weed control, soil cover and type of crops in rotation or intercropping) can be very different across broad locations and types of farms. A better understanding of which $\mathrm{CA}$ principles and related management practices contribute to the desired effects on crop productivity is important, particularly given the constraints that smallholder farmers often face in adopting all principles of CA as a package ${ }^{17,18}$.

Here we present the results of a comprehensive meta-analysis of crop yields under CA in sub-Saharan Africa. More specifically, our meta-analysis aimed to elucidate crop yield responses to CA and the agro-environmental and management conditions that favour positive crop responses. The latter, in particular, can contribute to a more effective targeting of investments in CA research and development in Africa, and thereby to increase crop production and food availability as part of a broader strategy to achieve sustainable food security.

The dataset used in the meta-analysis contains 933 observations from 79 studies that were conducted in 16 different countries in sub-Saharan Africa (Fig. 1, see Methods for the final data selection). Most reported research on CA in sub-Saharan Africa relates to cereal-based cropping systems. Cereals are the dominant staple

${ }^{1}$ Sustainable Intensification Program (SIP), International Maize and Wheat Improvement Center (CIMMYT), Nairobi, Kenya. ${ }^{2}$ Agro-ecology and Sustainable Intensification of Annual Crops (AIDA), French Agricultural Research Centre for International Development (CIRAD), University of Montpellier, Montpellier, France. ${ }^{3}$ Innovation Systems for the Drylands (ISD), International Crops Research Institute for the Semi-Arid Tropics (ICRISAT), Dar es Salaam, Tanzania. ${ }^{4}$ Tropical Plant Production and Agricultural Systems Modelling (TROPAGS), Georg August University of Göttingen, Göttingen,

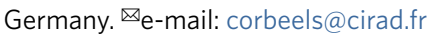


food crops in the maize mixed and agro-pastoral millet/sorghum farming systems, and to some extent in the cereal-root crop mixed and the highland temperate crop-livestock mixed farming systems ${ }^{19}$. Current and past development and promotional efforts with CA practices primarily involve these broad types of farming systems. To analyse the yield data, we developed a linear mixed-effects regression model of the CA-to-CT yield ratio as a framework for the meta-analysis, accounting for the yield variation both within and between studies. Next, we extended the model to investigate the effect of specific site and study descriptors (explanatory covariates) on the CA-to-CT yield ratio (see Methods). Our model with explanatory covariates fitted to the dataset $(n=933)$ explained a relatively high proportion of the variability in CA-to-CT yield ratios as indicated by the relatively high value of the conditional coefficient of determination $\left(r^{2}=0.88\right.$; Extended Data Fig. 1$)$.

\section{Results}

Yield responses to CA. Crop yields obtained under CA practices that comprised at least the principle of no- or reduced tillage were $3.7 \%$ (confidence interval $(\mathrm{CI}):[2.9,4.5]$ ) higher than those under CT (Fig. 2). In contrast, a previously published global meta-analysis ${ }^{14}$ concluded that no-tillage reduced yields by $5.1 \%$ for a range of crop species, and by $7.6 \%$ for maize. It should be noted that the global analysis compared CA and CT treatments that had the same crop residue additions and crop rotations to isolate the no-tillage effect, whereas our meta-analysis considered the cropping system level and focused on the yield effect of CA relative to CT in which crop residues were generally removed from the tilled field and continuous monocropping of cereals was typically practiced. This allowed us to use treatments that are appropriate representations of cropping system realities on African smallholder farms. On such farms, crop residues are commonly exported from the fields for cattle feed $^{20}$, whereas continuous cereal cropping is predominantly practiced without rotation for food security reasons ${ }^{21}$. The former global meta-analysis ${ }^{14}$ also mostly included data from field experiments on high-input cropping systems that were conducted in the context of mechanized farms (for example, more than $50 \%$ of the studies came from North America).

Yields were significantly higher under CA than under CT for maize (4.0\%, CI: $[2.8,5.2], P<0.0001)$ (Fig. 2), but no significant $(P>0.05)$ differences were found for the other crops (cotton, cowpea, rice, sorghum and soybean). Yield ratios differed significantly $(P<0.05)$ between soybean and some other crop species (Fig. 2), suggesting that the yield response to CA depends on the crop species. A large uncertainty range was found for cotton, resulting from the small sample size. There was substantial influence of individual observations on the weighted CA-to-CT yield ratio for this crop. Given the number of observations $(n=720)$, our results are most robust for maize.

Differential effects of CA principles. Maize yields under no- or reduced tillage alone (that is, without mulching and crop rotation/ intercropping: $\mathrm{RT}-\mathrm{M}-\mathrm{IR})$, were not significantly $(P>0.05)$ different from yields under CT. However, with mulching (RT $+M-I R)$, CA had a significantly positive effect on maize yields $(3.9 \%, \mathrm{CI}$ : $[2.5,5.3], P<0.0001)$. When all three CA principles are implemented $(\mathrm{RT}+\mathrm{M}+\mathrm{IR})$, the CA effect more than doubled $(8.4 \%$, CI: [6.1,10.8], $P<0.0001$ ) (Fig. 3).

These results indicate that the positive effect of CA on yields is caused by crop residue mulching and the use of crop rotations or intercropping. Mulching provides groundcover and adds organic matter to the soil with beneficial effects on several soil processes, including rainfall infiltration ${ }^{22}$, soil aggregation ${ }^{23}$, soil biological activity $^{24}$ and soil nutrient cycling ${ }^{25}$. Improved soil functioning can increase crop productivity, especially in low-input cropping systems with limited external nutrient supplies, such as those of smallholder

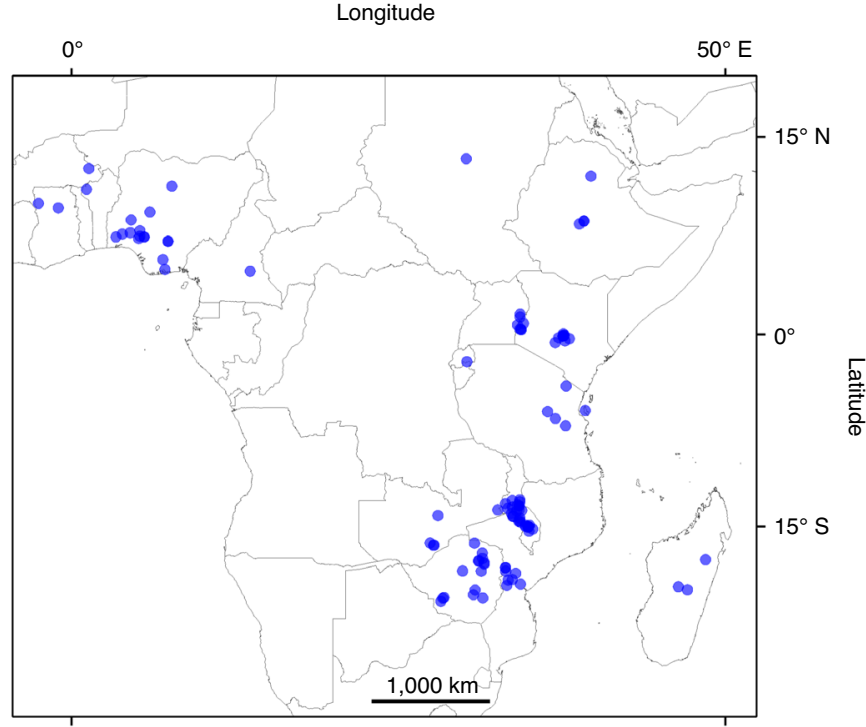

Fig. 1 | Location of the experiments considered in this meta-analysis. All experiments are from the studies containing yield comparisons between CA and CT systems. Created by GPSVisualizer.com; https://www. gpsvisualizer.com/.

farmers in sub-Saharan Africa. Mulching also diminishes weed emergence and growth, although substantial amounts of crop residues are required for these effects to occur ${ }^{26}$. Mulching can also reduce surface soil temperatures ${ }^{27}$, which can be favourable for early crop growth in the heat-stressed environments of the (sub)tropics. Yield benefits resulting from crop rotations and intercropping may to a great extent result from the disruption of pest and disease habitats and life cycles ${ }^{28}$ and, in the case of legumes, from adding nitrogen to the cropping system. Improved soil structure has also been observed with crop rotations or intercropping and is associated with differences in root development between the two (or more) dissimilar types of crops grown ${ }^{29}$.

Impact of CA over time. The results of our analysis support the claim that the crop yield performance of CA systems improves over time $e^{6,9,10}$, although the relative yield increase observed in our study is small $\left(1.05 \pm 0.26 \% \mathrm{yr}^{-1}\right)$ and the variability in the data is large (Fig. 4). Yield increases over time have often been attributed to gradually improved soil quality under CA versus $\mathrm{CT}^{30,31}$. However, a recent analysis of data published in studies from sub-Saharan Africa $^{32}$ did not find a substantial overall increase of soil organic carbon under CA over time. The study revealed a scarcity of good-quality data of soil organic carbon contents from field studies in sub-Saharan Africa. More observations from long-term studies are clearly needed to establish whether a relationship exists between increased crop yields, improved soil quality and the duration of the practice of CA.

Management and agro-environmental effects. The use of herbicides in the CA treatments was a significant covariate $(F=6.22$, $P<0.005$, Extended Data Fig. 1) explaining the crop yield response to CA compared with CT. With the use of herbicides, CA yields were $4.7 \%$ (CI: $[3.5,5.6], P<0.0001)$ higher than CT yields; without herbicides, no significant $(P>0.05)$ yield difference was found (Fig. 5). The better performance of CA when using herbicides is expected, as chemical weeding is generally more effective than mechanical (hand)weeding ${ }^{33}$ in controlling the increased weed pressure in the absence of tillage ${ }^{34}$. For example, with mechanical 


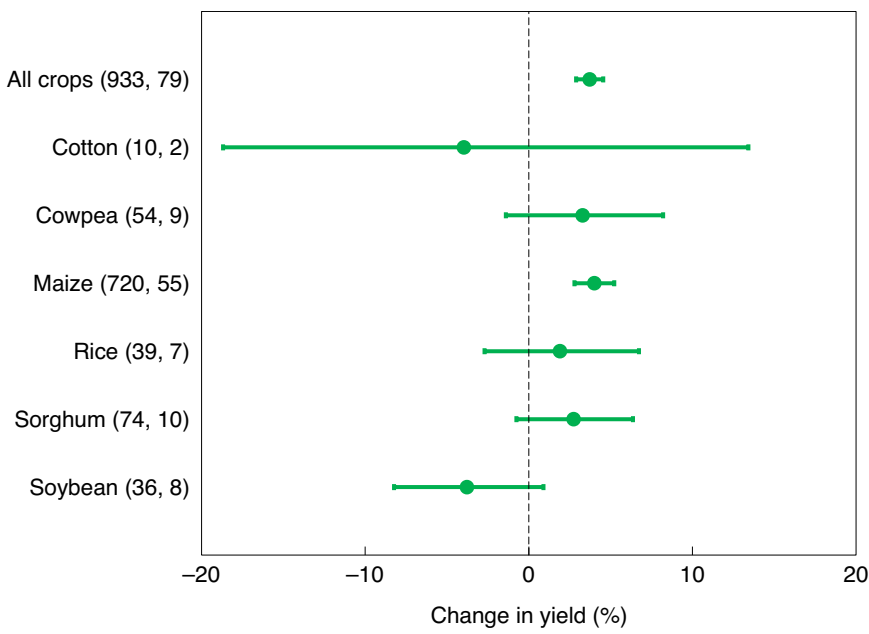

Fig. 2 | Effect of CA relative to CT on grain yield for different crop species. Values are mean effect sizes and error bars show the $95 \% \mathrm{Cl}$. The number of observations and studies for each category are shown in parentheses. The mean effect sizes were considered significant if the $95 \% \mathrm{Cl}$ does not include 0 . The $C A$ effect on yields is significantly $(P<0.05)$ higher for cowpea, maize and sorghum than for soybean, as determined via paired Student's t-tests.

weeding it is difficult to control the weeds that are emerging close to the crop plants, whereas pre-emergent herbicides are particularly effective at eliminating weed competition during the critical initial stages of crop growth.

Although it has been argued that fertilizer applications improve the performance of CA by avoiding crop nutrient stresses that result from nutrient immobilization with crop residue mulching $^{25,35}$, our results did not show evidence of increasing CA-to-CT yield ratios with higher nitrogen or phosphorus fertilizer applications (Fig. 6, and Extended Data Fig. 1). On the contrary, we found that CA outperformed CT at the lowest phosphorus fertilization rates of $0-20 \mathrm{~kg} \mathrm{Pha}^{-1}(P<0.0001)$ and $20-40 \mathrm{~kg} \mathrm{Pha}^{-1}(P<0.05)$; these effects were significantly $(P<0.05)$ higher than the effect at 40-60 kg Pha ${ }^{-1}$, which showed a negative mean CA-to-CT yield ratio (Fig. 6). The results suggest the complexity of the effects of nutrient inputs on crop growth in CA versus CT systems. Soil type, climate conditions, the use of varying quantities and types of mulch and the presence of legumes in the CA cropping systems certainly interfere with fertilizer effects on the relative crop yield response to CA, but this could not be quantified from our database. It should, however, be recognized that the appropriate use of fertilizer is essential for smallholder farmers in sub-Saharan Africa to obtain high yields and increased supplies of crop residues for the practice of $\mathrm{CA}^{36}$.

The relative yield performance of CA was affected by climate as indicated by the significant covariate effect of average seasonal rainfall $(F=3.86, P<0.05$, Extended Data Fig. 1$)$. This finding corroborates results of other studies ${ }^{37,38}$. We found decreasing CA-to-CT yield ratios with increasing rainfall (Fig. 7). CA yields were $12.5 \%$ (CI: [4.2, 21.4], $P<0.005$ ), 4.5\% (CI: [2.9, 6.1], $P<0.0001)$ and 3.9\% (CI: $[2.3,5.6], P<0.0001$ ) higher than $\mathrm{CT}$ yields at sites with respectively $<400 \mathrm{~mm}, 400-800 \mathrm{~mm}$ and $800-1,200 \mathrm{~mm}$ of seasonal rainfall. In contrast, at sites with $>1,200 \mathrm{~mm}$ of seasonal rainfall, yields were significantly lower under CA than CT $(-4.3 \%$, CI: $[-7.6,-0.8], P<0.05)$.

These results indicate that the largest yield benefits from CA occur in the lowest range of the suitable rainfall regimes for maize growth, which are often characterized by dry spells. The positive effect of CA on yield in these conditions can mainly be attributed

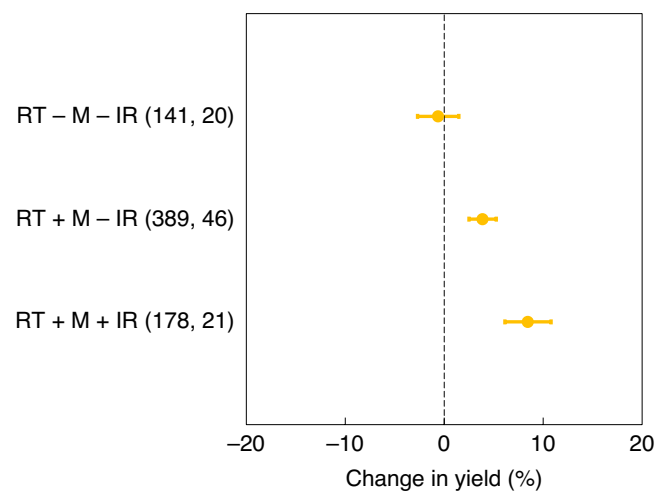

Fig. 3 | Effect of CA relative to CT on maize grain yield under different combinations of CA principles. Values are mean effect sizes and error bars show the $95 \% \mathrm{Cl}$. The number of observations and studies for each category are shown in parentheses. The mean effect sizes were considered significant if the $95 \% \mathrm{Cl}$ does not include 0 . The CA effect on maize yield is significantly different $(P<0.0005)$ between $R T-M-I R, R T+M-I R$ and $R T+M+I R$, as determined via paired Student's $t$-tests.

to soil moisture conservation as a result of crop residue mulching, which leads to improved rainfall-use efficiency of crops $^{39}$. It is known that crop residue mulching decreases soil water evaporation $\operatorname{losses}^{26,40}$ and can increase soil water infiltration ${ }^{22,26}$. On the other hand, the negative yield effects of CA under high rainfall are often attributed to prolonged waterlogging conditions under mulching ${ }^{41}$. As a result of the water conservation effects, CA has increasingly been endorsed as a 'climate-smart agriculture' practice that can contribute to adaptation to climate change ${ }^{9,42}$. However, it is precisely in the dry climates of sub-Saharan Africa that crop biomass production is low and livestock numbers are high, leading to intense competition for crop residues between use as soil cover and feed for cattle ${ }^{20}$. This means that, in these regions, mulching with crop residues often poses a serious challenge to farmers; feeding of crop residues to livestock is often preferred over soil mulching, as livestock is essential for the provision of meat and milk, of traction and manure, as well as being a means of accumulating capital and managing risks in farming ${ }^{43}$.

Our meta-analysis also revealed a significant interaction of average seasonal rainfall and soil texture $(F=3.38, P<0.01$, Extended Data Fig. 1) explaining the crop yield responses to CA compared with CT. Under seasonal rainfall below $800 \mathrm{~mm}$, CA outperformed CT on all soil types $(P<0.05)$, with no significant $(P>0.05)$ differences between soil types (Extended Data Fig. 2). However, under the $800-1,200 \mathrm{~mm}$ rainfall regime, CA outperformed CT only on the coarse-textured soils $(4.7 \%, \mathrm{CI}$ : $[2.8,6.7], P<0.0001)$ that are known to be prone to erratic crop water stress. The negative CA-to-CT yield ratio on medium-textured soils was significantly $(P<0.05)$ lower than on the two other soil types. Under high rainfall $(>1,200 \mathrm{~mm})$, there was a significantly $(P<0.01)$ negative CA effect on the medium- and fine-textured soils, probably due to the higher risk of waterlogging on these soil types ${ }^{41}$, whereas the CA effect was zero on the sandy soils. More data (including actual, rather than average seasonal rainfall data) are needed to uncover further evidence of climate-soil interactions, including specific measurements in field experiments to reveal the mechanisms behind these interactions.

Smallholder farmers in sub-Saharan Africa use different operational forms of no- or reduced tillage, largely depending on the resources available to them. No-tillage systems range from simply planting in a hole made with a pointed stick, to the use of the more sophisticated jab planter or animal-drawn direct seeder (Extended Data Fig. 3a-c). In minimum-tillage systems, a furrow is created 


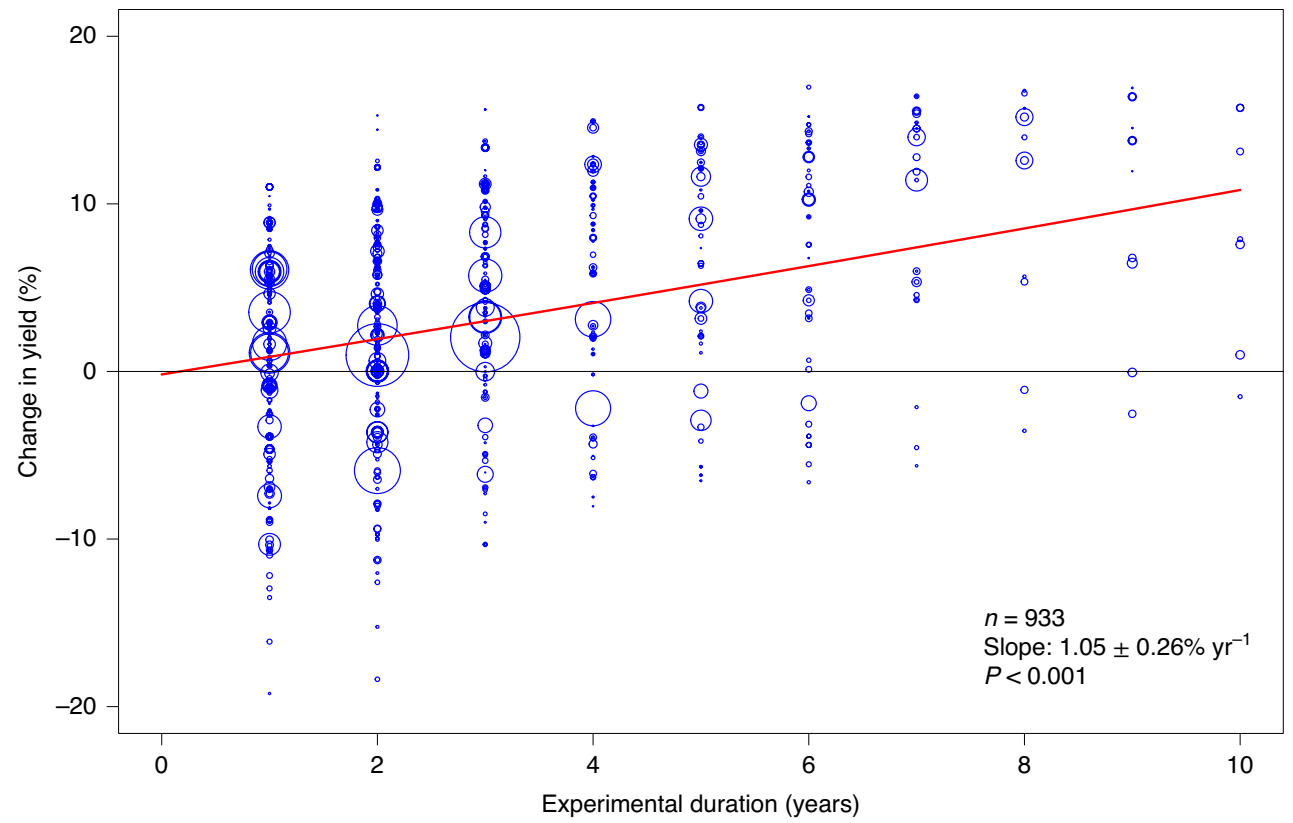

Fig. 4 | Effect of CA relative to CT on crop grain yield in relation to experimental duration. Experimental duration is the number of years under continuous CA. The circles display the CA-to-CT yield ratios for each observation, with circle sizes proportional to the relative weight of each observation. The red line represents the fitted random-effects model regression. The slope of the regression line is given as the mean \pm 1 s.d.

using a hand hoe or an animal-drawn ripper (Extended Data Fig. 3d). The hand hoe-made planting basins are intended for smallholders in semi-arid regions with no or limited access to draught animals (Extended Data Fig. 3e). Our results show that the type of reduced tillage in the CA treatment had a significant effect on the CA-to-CT yield ratio $(F=7.06, P<0.005)$. CA outperformed CT $(4.6 \%, \mathrm{CI}:[3.4,5.8], P<0.0001)$ only in the case of no-tillage systems, and its relative yield performance was significantly higher than with minimum-tillage systems $(P<0.005)$ or planting basins/ permanent beds $(P<0.05)$ (Extended Data Fig. 4). Planting basins are essentially a soil and water conservation technology, the positive impact of which on yield largely depend on the seasonal rainfall pattern ${ }^{44}$. It should also be noted that where no-tillage is applied with an animal-drawn direct seeder, seeds and fertilizer are more uniformly distributed at the desired application rates, which could confound the yield effect of no-tillage per se.

We found a significant effect of study type on the relative yield performance of CA ( $F=4.49, P<0.05$, Extended Data Fig. 1); relative CA yields in studies conducted on farmers' fields (on-farm trials) were higher than those conducted on experimental stations (Extended Data Fig. 5). This is a surprising result that we cannot immediately explain. The analysis of the funnel plot with on-farm versus on-station studies (Extended Data Fig. 6) revealed that on-farm studies have a slight tendency towards positive effects of CA relative to CT (skewness $T_{\mathrm{S}}$ is $0.18, P=0.07$ ), whereas on-station studies had a slight tendency towards negative effects $\left(T_{\mathrm{S}}=-0.26\right.$, $P=0.05)$. With respect to on-farm trials, it has been argued that the different interests of researchers, extension agents and farmers tend to converge around 'positive' trial results-that is, researcher-defined CA treatments outperforming the control CT treatments that are constructed as the conventional farmer practices ${ }^{45}$. This may somehow involve the introduction of some selective bias in on-farm trials, although not necessarily deliberately.

\section{Discussion}

Our results have important implications for the promotion of CA as a pathway for the sustainable intensification of crop production

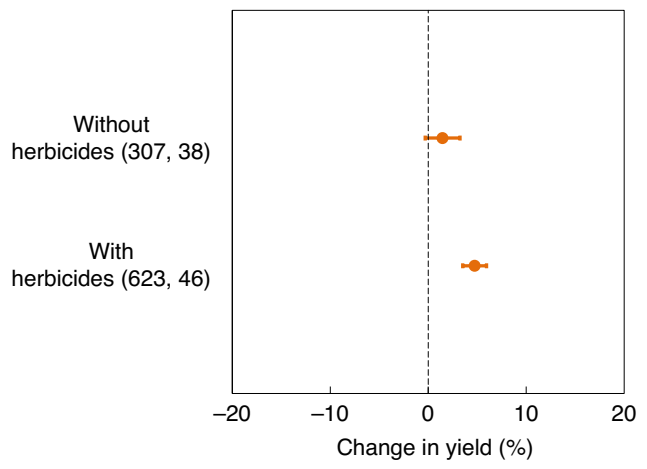

Fig. 5 | Effect of CA relative to CT on crop grain yield as a function of herbicide use in the CA treatment. Values are mean effect sizes and error bars show the $95 \% \mathrm{Cl}$. The number of observations and studies for each category are shown in parentheses. The mean effect sizes were considered significant if the $95 \% \mathrm{Cl}$ does not include 0 . The CA effect on yield is significantly $(P<0.005)$ higher with herbicides than without herbicides.

and increased food production in sub-Saharan Africa. First, the crop yield benefits that can be expected from CA are relatively small. Beyond the aspect of crop productivity, a widely recognized advantage of no- or reduced tillage is the elimination of time- and energy-consuming ploughing 5 . However, studies ${ }^{46,47}$ have shown that increases in profitability through cost reductions that could be realized with CA are usually small in the case of smallholder farmers, in contrast with observations for large, mechanized farms. On the other hand, it should be noted that our meta-analysis could not investigate possible crop yield benefits from CA associated with more timely sowing opportunities leading to better early crop establishment ${ }^{48}$. In the studies included in our meta-analysis, the CA and CT experimental treatments had the same sowing date. This is one of the simplifications of cropping systems in field experiments and in our meta-analysis. We hereby acknowledge that the real-world 


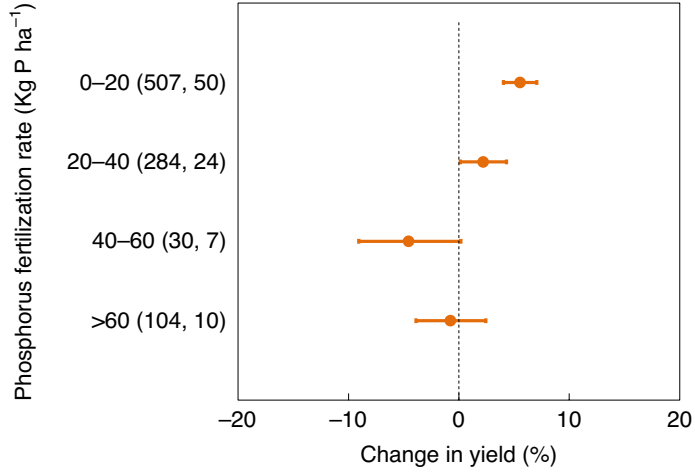

Fig. 6 | Effect of CA relative to $\mathrm{CT}$ on crop grain yield as a function of applied chemical phosphorus fertilizer. Values are mean effect sizes and error bars show the $95 \% \mathrm{Cl}$. The number of observations and total number of studies for each category are shown in parentheses. The mean effect sizes were considered significant if the $95 \% \mathrm{Cl}$ does not include 0 . The CA effect on yield is significantly $(P<0.05)$ higher at $0-20 \mathrm{~kg} \mathrm{Pha}^{-1}$ than at the three other fertilizer levels, and the effect at $20-40 \mathrm{~kg} \mathrm{Pha}^{-1}$ is significantly $(P<0.01)$ higher than at $40-60 \mathrm{~kg} \mathrm{Pha}^{-1}$, as determined via paired Student's $t$-tests.

cropping systems are not as simple as the experimental settings. Therefore, the implications of the results of our meta-analysis should be cautiously interpreted, and higher level processes and contextual interactions beyond the field level should be considered ${ }^{49}$.

Second, partial adoption of no- or reduced tillage only is not an option to enhance crop productivity. To be successful, CA needs to be fully implemented (that is, alongside mulching and crop rotation or intercropping). The latter two principles are, however, not easy to adopt for many smallholder farmers in sub-Saharan Africa, who manage mixed crop-livestock systems ${ }^{11,17}$. Crop residues have several other uses on the farm, especially as feed for livestock ${ }^{20}$. Legumes are often disregarded as rotation crops or intercrops, as functional markets for their sale are often unavailable. Besides, although the inclusion of legumes in a rotation contributes to higher yields for the subsequent crop, it may have negative effects on the total production of the cropping system as legume yields are usually smaller than cereal yields. This is another factor that may discourage smallholders from adopting the whole CA package. Thus, as farmers' decisions on resource allocation are not reflected in small-plot field experiments, caution is needed when upscaling the findings from the experiments to the farm (and higher) level ${ }^{49}$. Moreover, crop yield increases of a few percentage points are often meaningless on smallholder farms in terms of farm-level indicators such as food security and income ${ }^{50}$.

Third, the use of herbicides is a prerequisite for positive yield effects of CA. However, herbicides may be beyond the grasp of many smallholder farmers in sub-Saharan Africa, who generally lack the resources for purchasing them. Moreover, herbicide use has negative impacts on the environment and human health ${ }^{51}$, thus compromising the sustainability of CA systems. It is generally known that the repeated use of specific herbicides such as glyphosate may lead to the rapid evolution of herbicide-resistant weeds ${ }^{52,53}$ and have residual effects in soils, water or food ${ }^{54}$.

Finally, our analysis showed the highest relative yield benefits from CA in conditions of low rainfall. In general, immediate positive CA yield effects are observed when water stress occurs during crop growth, because of the positive effect of mulching on the soil water balance ${ }^{26,39}$. This indicates that the highest immediate return on investment in CA research and development is to be expected in regions experiencing recurrent and prolonged dry spells.

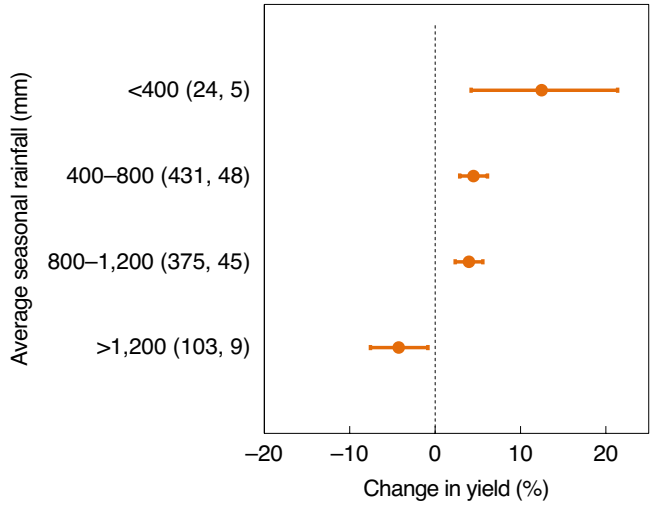

Fig. 7 | Effect of CA relative to CT on crop grain yield as a function of average seasonal rainfall at the experimental site. Values are mean effect sizes and error bars show the $95 \% \mathrm{Cl}$. The number of observations and studies for each category are shown in parentheses. The mean effect sizes were considered significant if the $95 \% \mathrm{Cl}$ does not include 0 . The CA effect on yield is significantly $(P<0.0005)$ lower at sites with seasonal rainfall of $>1,200 \mathrm{~mm}$ than at the sites with the drier rainfall regimes, and the effect at sites with seasonal rainfall of $800-1,200 \mathrm{~mm}$ is significantly $(P<0.05)$ lower than at sites with seasonal rainfall of $<400 \mathrm{~mm}$, as determined via paired Student's t-tests.

Overall, we conclude that the practice of CA is not a technology that allows smallholder farmers to overcome low crop productivity and food insecurity in the short term. There are, however, other important criteria by which the performance of cropping systems or their contribution to a broader sustainability agenda can be evaluated-including yield stability and environmental benefits such as reduced soil erosion, improved soil quality and biodiversity protection. CA has been proven to avert soil degradation and improve soil quality ${ }^{5,7}$. The crop yield increases over time under CA relative to $\mathrm{CT}$ that we found in our study may be related to these processes. To further investigate this, appropriate investments in long-term experiments across agro-ecological zones in Africa are urgently needed.

\section{Methods}

Literature search. A comprehensive search was conducted for peer-reviewed publications on the effect of CA on crop yields compared to CT in sub-Saharan Africa using the online databases ISI Web of Science (Thomson Reuters) and Scopus (Elsevier). The following search terms were used (an asterisk being a replacement for any ending of the respective term): 'conservation agriculture', 'zero till*', 'no till*', 'reduced till*, 'minimum till ${ }^{*}$, 'direct seeding', or 'direct drill ${ }^{*}$ in combination with 'yield' and 'Africa' or a country from the list of all countries of sub-Saharan Africa (excluding South Africa and Lesotho) in the publication title, abstract or keywords. The database searches were augmented with searches of library resources for relevant papers from citations in retrieved papers. The last search was done in December 2019.

Eligibility criteria. Studies from the retrieved publications were screened and had to meet the following defined basic selection criteria to be included in the meta-analysis. First, studies report crop yields from field experiments in which a CT treatment is compared with a (partial) CA treatment using statistical methods Second, the effect of no- or reduced tillage must be tested with the CA treatment. Third, the experiments must be conducted under rain-fed field conditions in a specified location in sub-Saharan Africa. Fourth, the mean, sample size and standard deviation of crop yields must be directly reported as numerical or graphical data or can be calculated from the reported data. Standard deviations were calculated from standard errors, coefficients of variation, 95\% CI or least significant differences in cases where they were not reported in the papers. For some observations, the least significant difference was estimated as the smallest difference between the mean values of treatments that were still significant. Data from the same study that were reported in more than one publication were not repeated to avoid double counting; instead, the data from the most recent publication were used. Observations were excluded from the analysis when only average crop yields over seasons or sites were presented. If more than one form of tillage was assessed in a study, we selected the CT treatment that represented the 
greatest soil disturbance. Studies were rejected if crop management practices other than those related to the three CA principles (RT, M and IR) differed between CA and CT treatments, with the exception of weed management. Tillage in CT systems helps with the control of weeds, and its absence in CA systems often implies the use of herbicides and/or additional mechanical weeding. In total, 87 publications were selected, giving $992 \mathrm{CA}$-to-CT yield comparisons. The complete reference list of publications is given in Supplementary Table 1.

Database. Yield data for the different crop species (barley, bean, cotton, cowpea, grass pea, maize, millet, pigeon pea, rice, sorghum, soybean, teff, wheat and mixtures of wheat and barley) found in the selected 87 publications were extracted. To explain heterogeneity in study outcomes, we also compiled information on several study and site descriptors that may have influenced the yield response to CA. The a priori selected candidate explanatory variables were: type of tillage in the CT treatment (hoe, plough or ridging), type of reduced tillage in the CA treatment (no-tillage, minimum tillage or basins/permanent beds), mulch type (cereals, cotton, legumes, mixture of cereals and legumes, non-cereal grasses or forest litter), initial mulch amount (in $\mathrm{kg}$ of dry matter per ha), presence of legumes in the rotation or intercropping (yes/no), type of field trial (on-station or on-farm trial), altitude of study site $(\mathrm{m})$, actual seasonal rainfall during the experiment $(\mathrm{mm})$, average seasonal rainfall at the site of the experiment $(\mathrm{mm})$, average annual temperature $\left({ }^{\circ} \mathrm{C}\right.$ ), soil texture (categorized as coarse, medium or fine, following the soil texture classes as defined by the United States Department of Agriculture), soil carbon content of topsoil layer $\left(\mathrm{g} \mathrm{C} \mathrm{kg}^{-1}\right)$, use of herbicides with CA (yes/no), number of years since the implementation of CA, and applied chemical nitrogen and phosphorus fertilizer $\left(\mathrm{kg} \mathrm{ha}^{-1}\right)$. Information for these variables was extracted from the text, tables or figures in the publications, when available. If not reported, average seasonal rainfall and annual temperature data were retrieved from the New_LocClim 1.10 database ${ }^{55}$ using the latitude and longitude coordinates of the study site. If latitude and longitude coordinates and/or altitude were not reported in the publication they were searched with Google Maps using the name of the site at which the study took place. Average seasonal rainfall was classified into four categories: $<400 \mathrm{~mm}, 400-800 \mathrm{~mm}, 800-1,200 \mathrm{~mm}$ and $>1,200 \mathrm{~mm}$. Nitrogen fertilizer applied was categorized as follows: 0-20, 20-50, $50-100$ and $>100 \mathrm{~kg} \mathrm{Nha}^{-1}$, and phosphorus fertilizer applied as 0-20, 20-40, $40-60$ and $>60 \mathrm{~kg} \mathrm{Pha}^{-1}$. In some cases, the authors of the studies were contacted for additional information and/or clarification on the retrieved data. Values for the explanatory variables were left blank when information could not be retrieved.

Data analysis. The natural logarithm of the ratio of CA:CT grain yields was used as the effect size metric in the meta-analysis. The use of the natural logarithm linearizes the metric and provides more normal sampling distribution in small samples ${ }^{56}$. For ease of interpretation, results were back-transformed and presented as percentage change in crop yield from the CA relative to the CT treatment. We distinguished three levels of CA in the analysis that represent different combinations of CA principles: RT $-\mathrm{M}-\mathrm{IR}, \mathrm{RT}+\mathrm{M}-\mathrm{IR}$ and $\mathrm{RT}+\mathrm{M}+\mathrm{IR}$.

Individual response ratios were weighted by the reciprocal of their respective estimated variances as a measure of study quality; that is, observations with low variance were considered more reliable and received a higher weight in the meta-analysis. As expected, the on-farm trials had a significantly $(P<0.0001)$ higher variance, thus smaller weight, than on-station trials (Extended Data Fig. 7 ). We acknowledge that a validity assessment of the studies could also be used as weighting factor, so that possibly more valid or accurate studies have more influence on the size effects. For example, on-farm trials may be more valid with respect to real farming conditions. However, validity assessments would require a numerical summary of validity for each study, and there is no empirical basis for determining how much weight to assign to degrees of validity of for example on-station versus on-farm trials. Therefore, it has been recommended that direct weighting of effect estimates by validity assessments of risk of bias should be avoided ${ }^{57}$. In this context, it should also be noted that the set-up of on-farm trials was highly heterogeneous across the retrieved studies, ranging from fully researcher-managed and farmer-implemented trials to fully farmer-managed and farmer-implemented trials.

We assumed that, for a given observation, the variances of the CA and CT treatments were approximately equal. The variance of the response ratio $\left(V_{\operatorname{lnRR}}\right)$ can then be approximated using the pooled standard deviation $\left(\mathrm{SD}_{\mathrm{P}}\right)$ as follows ${ }^{58}$ :

$$
V_{\mathrm{lnRR}}=\mathrm{SD}_{\mathrm{p}}^{2 \star}\left(\frac{1}{n_{\mathrm{CA}}{ }^{\star} \bar{X}_{\mathrm{CA}}^{2}}\right)+\left(\frac{1}{n_{\mathrm{CT}}{ }^{\star} \bar{X}_{\mathrm{CT}}^{2}}\right),
$$

where $n$ is the number of replicates and $\bar{X}$ the mean.

The following crop species had few observations resulting in confounding problems of explanatory variables that are correlated (that is, the type of tillage in the CA treatment, rainfall class or soil texture class), and were therefore not included in the meta-analysis: millet ( 8 observations, 1 study), teff ( 7 observations, 3 studies), bean ( 4 observations, 2 studies), pigeon pea ( 4 observation, 1 study), grass pea ( 3 observations, 2 studies), wheat ( 21 observations, 5 studies), barley (4 observations, 2 studies) and the mixture of barley and wheat ( 2 observations, 1 study). Besides, the RT $-\mathrm{M}-$ IR treatment for rice ( 6 observations, 1 study) was not included for the same reasons. A total of 933 observations from 79 studies were included in the meta-analysis.

First, the overall mean CA-to-CT yield ratio across the 933 observations was calculated using the random-effects model for meta-analysis ${ }^{58}$. Next, we analysed the yield response ratio for the different crop species as function of CA level (different combinations of CA principles), using the following linear mixed-effects model:

$$
Y_{i j k l}=\mu+\alpha_{i}+\beta_{i j}+C_{i k}+D_{i j k}+\varepsilon_{i j k l},
$$

where $Y_{i j k l}$ is the natural logarithm of the observed ratio of CA-to-CT grain yields for crop species $i$, CA level $j$, trial $k$ and observation $l ; \mu$ is the mean response ratio across studies; $\alpha_{i}$ is the fixed effect of crop species; $\beta_{i j}$ is the fixed effect of $j$ for $i$; $C_{i k}$ is the random effect of $k$ for $i$; $D_{i j k}$ is the random effect of the interaction between $j$ and $k$ for $i$; and $\varepsilon_{i j k l}$ is the residual error.

The CA level factor was nested within crop species because of collinearity between both factors. The trial factor (that is, the ensemble of individual CA observations that have the same CT control for a given year) and its interaction with CA level were introduced as random effects to account for the hierarchical dependence between multiple observations within a study ${ }^{59}$. A first-order autocorrelation structure $[\mathrm{AR}(1)]$ was included in the model to account for repeated observations within one trial not being independent over years.

Finally, we extended the above model to determine the influence of certain specific study and site descriptors (explanatory covariates) on the yield response ratio, as follows:

$$
Y_{i j k l}=\mu+\alpha_{i}+\beta_{i j}+\sum_{m}\left(a_{m} \times X_{i j k l}^{m}\right)+C_{i k}+D_{i j k}+\varepsilon_{i j k l},
$$

where $X^{m}$ is the $m$ explanatory covariates with their coefficients $a^{m}$.

To produce a robust analysis, several candidate explanatory variables were excluded due to high or moderate collinearity with other variables (altitude of the study site and average annual temperature). Other variables (the initial mulch amount, actual seasonal rainfall during the experiment and soil carbon content) were not included because there were too many missing values in the dataset. Variables were sequentially added to and dropped from the model based on $F$ statistics (variables with $F<1$ were eliminated) until the goodness of fit (the Akaike Information Criterion) was not reduced by adding variables. The resulting model included the following covariates as fixed effect terms: (1) type of reduced tillage in the CA treatment, (2) type of field trial, (3) average seasonal rainfall, (4) herbicide use in the CA treatment, (5) applied chemical phosphorus fertilizer, (6) number of years since the implementation of CA and (7) the average seasonal rainfall and soil texture class interaction.

The model parameters were estimated by the restricted maximum likelihood approach. Estimated mean response ratios were considered statistically different from zero (that is, the CA yield is significantly different from the CT yield) if their $95 \%$ CI did not overlap zero; the CIs were calculated by multiplying the standard error by the $95 \%$ point of the Student's $t$-test distribution corresponding to the number of degrees of freedom. Paired Student's $t$-tests on the logarithmic difference of response ratios between two subgroups of studies were performed to determine whether the CA-to-CT yield ratios differed significantly between the two groups.

Publication bias in the dataset was assessed by the use of a funnel plot $^{60}$, where the data points plotted against the corresponding standard errors represent the marginal deviations of the logarithmic yield ratios from the fixed effects, added to the average logarithmic yield ratio for maize (as a reference). This implies that the heterogeneity accounted for by the covariates is subtracted, and the funnel plot shows random between-trial effects, random effects of the interaction between CA level and trial plus the sampling error effects. Funnel plot asymmetry was tested with $T_{\mathrm{S}}$ of the marginal deviations ${ }^{61}$. This test quantifies the departure of the deviations' distribution from symmetry.

Asymmetry in the funnel plot suggests publication bias. In our study, the funnel plot was sufficiently symmetrical (Extended Data Fig. 6); the $P$ value of $T_{\mathrm{S}}$ was large, from which we concluded that there was no publication bias within the studies considered in our meta-analysis.

All statistical analyses were performed with PROC MIXED in the statistical software package SAS version 9.3 (ref. ${ }^{62}$ ).

Reporting Summary. Further information on research design is available in the Nature Research Reporting Summary linked to this article.

\section{Data availability}

The data used in this study are available from the Dataverse repository at https:// doi.org/10.18167/DVN1/DLTQWR.

\section{Code availability}

Scripts used in the literature search and statistical analyses are available from the corresponding author on request. 
Received: 26 September 2019; Accepted: 19 June 2020;

Published online: 16 July 2020

\section{References}

1. OECD-FAO Agricultural Outlook 2016-2025 59-95 (OECD, 2016).

2. Van Ittersum, M. K. et al. Can sub-Saharan Africa feed itself? Proc. Natl Acad. Sci. USA 113, 14964-14969 (2016).

3. Garnett, T. et al. Sustainable intensification in agriculture: premises and policies. Science 341, 33-34 (2013).

4. Godfray, H. C. J. \& Garnett, T. Food security and sustainable intensification. Phil. Trans. R. Soc. B 369, 20120273 (2014).

5. Hobbs, P., Sayre, K. \& Gupta, R. The role of conservation agriculture in sustainable agriculture. Phil. Trans. R. Soc. B 363, 543-555 (2008).

6. Pretty, J. \& Bharucha, Z. Sustainable intensification in agricultural systems. Ann. Bot. 114, 1571-1596 (2014).

7. Benites, J. R. \& Ashburner, J. E. in Conservation Agriculture: Environment, Farmers Experiences, Innovations, Socio-economy, Policy (eds Garcia-Torres, L. et al.) 139-153 (Kluwer Academic, 2003).

8. Andersson, J. A. \& D'Souza, S. From adoption claims to understanding farmers and contexts: a literature review of Conservation Agriculture (CA) adoption among smallholder farmers in southern Africa. Agric. Ecosyst. Environ. 187, 116-132 (2014).

9. Kassam, A., Friedrich, T. \& Derpsch, R. Global spread of conservation agriculture. Int. J. Environ. Stud. 76, 29-51 (2019).

10. Thierfelder, C., Matemba-Mutasa, R. \& Rusinamhodzi, L. Yield response of maize (Zea mays L.) to conservation agriculture cropping system in Southern Africa. Soil Till. Res. 146, 230-242 (2015).

11. Giller, K. E., Witter, E., Corbeels, M. \& Tittonell, P. Conservation agriculture and smallholder farming in Africa: the heretics' view. Field Crops Res. 114, 23-34 (2009).

12. Stevenson, J. R., Serraj, R. \& Cassman, K. G. Evaluating conservation agriculture for small-scale farmers in sub-Saharan Africa and South Asia. Agric. Ecosyst. Environ. 187, 1-10 (2014)

13. Brouder, S. M. \& Gomez-Macpherson, H. The impact of conservation agriculture on smallholder agricultural yields: a scoping review of the evidence. Agric. Ecosyst. Environ. 187, 11-32 (2014).

14. Pittelkow, C. M. et al. Productivity limits and potentials of the principles of conservation agriculture. Nature 517, 365-368 (2015).

15. Erenstein, O., Sayre, K., Wall, P., Hellin, J. \& Dixon, J. Conservation agriculture in maize- and wheat-based systems in the (sub)tropics: lessons from adaptation initiatives in South Asia, Mexico, and Southern Africa. J. Sustain. Agric. 36, 180-206 (2012).

16. Giller, K. E. et al. Beyond conservation agriculture. Front. Plant Sci. 6 , 870 (2015).

17. Grabowski, P. P., Kerr, J. M., Haggblade, S. \& Kabwe, S. Determinants of adoption and disadoption of minimum tillage by cotton farmers in eastern Zambia. Agric. Ecosyst. Environ. 231, 54-67 (2016).

18. Brown, B., Nuberg, I. \& Llewellyn, R. Stepwise frameworks for understanding the utilisation of conservation agriculture in Africa. Agric. Syst. 153, 11-22 (2017)

19. Dixon, J., Gulliver, A. \& Gibbon, D. Farming Systems and Poverty: Improving Farmers' Livelihoods in a Changing World (FAO, 2001).

20. Valbuena, D. et al. Conservation agriculture in mixed crop-livestock systems: scoping crop residue trade-offs in Sub-Saharan Africa and South Asia. Field Crops Res. 132, 175-184 (2012).

21. Frelat, R. et al. Drivers of household food availability in sub-Saharan Africa based on big data from small farms. Proc. Natl Acad. Sci. USA 113 458-463 (2016).

22. Findeling, A., Ruy, S. \& Scopel, E. Modeling the effects of a partial residue mulch on runoff using a physically based approach. J. Hydrol. 275, 49-66 (2003).

23. Beare, M. H., Cabrera, M. L., Hendrix, P. F. \& Coleman, D. C. Aggregate-protected and unprotected organic matter pools in conventionaland no-tillage soils. Soil Sci. Soc. Am. J. 58, 787-795 (1994).

24. Tian, G., Brussaard, L. \& Kang, B. T. Biological effects of plant residues with contrasting chemical compositions under humid tropical conditions: effects on soil fauna. Soil Biol. Biochem. 25, 731-737 (1993).

25. Schoenau, J. J. \& Campbell, C. A. Impact of crop residues on nutrient availability in conservation tillage systems. Can. J. Plant Sci. 76, 621-626 (1996).

26. Ranaivoson, L. et al. Agro-ecological functions of crop residues under conservation agriculture: a review. Agron. Sustain. Dev. 37, 26 (2017).

27. Bussiere, F. \& Cellier, P. Modification of the soil temperature and water content regimes by a crop residue mulch: experiment and modelling. Agric. For. Meteorol. 68, 1-28 (1994).

28. Ratnadass, A., Fernandes, P., Avelino, J. \& Habib, R. Plant species diversity for sustainable management of crop pests and diseases in agroecosystems: a review. Agron. Sustain. Dev. 32, 273-303 (2012).
29. Ball, B. C., Bingham, I., Rees, R. M., Watson, C. A. \& Litterick, A. The role of crop rotations in determining soil structure and crop growth conditions. Can. J. Soil Sci. 85, 557-577 (2005).

30. de Oliveira Ferreira, A. et al. Can no-till grain production restore soil organic carbon to levels natural grass in a subtropical Oxisol? Agric. Ecosyst. Environ. 229, 13-20 (2016).

31. Tuzzin de Moraes, M. et al. Soil physical quality on tillage and cropping systems after two decades in the subtropical region of Brazil. Soil Till. Res. 155, 351-362 (2016)

32. Corbeels, M., Cardinael, R., Naudin, K., Guibert, H. \& Torquebiau, E. The 4 per 1000 goal and soil carbon storage under agroforestry and conservation agriculture systems in sub-Saharan Africa. Soil Till. Res. 188, 16-26 (2019).

33. Pleasant, J. M. T., Burt, R. F. \& Frisch, J. C. Integrating mechanical and chemical weed management in corn (Zea mays). Weed Technol. 8, 217-223 (1994).

34. Nichols, V., Verhulst, N., Cox, R. \& Govaerts, B. Weed dynamics and conservation agriculture principles: A review. Field Crops Res. 183, 56-68 (2015).

35. Williams, A. et al. Establishing the relationship of soil nitrogen immobilization to cereal rye residues in a mulched system. Plant Soil 426, 95-107 (2018).

36. Vanlauwe, B. et al. A fourth principle is required to define conservation agriculture in sub-Saharan Africa: the appropriate use of fertilizer to enhance crop productivity. Field Crops Res. 155, 10-13 (2014).

37. Rusinamhodzi, L. et al. A meta-analysis of long-term effects of conservation agriculture on maize grain yield under rain-fed conditions. Agron. Sustain. Dev. 31, 657 (2011)

38. Steward, P. R. et al. The adaptive capacity of maize-based conservation agriculture systems to climate stress in tropical and subtropical environments: a meta-regression of yields. Agric. Ecosyst. Environ. 251, 194-202 (2018).

39. Scopel, E., Da Silva, F. A. M., Corbeels, M., Affholder, F. \& Maraux, F. Modelling crop residue mulching effects on water use and production of maize under semi-arid and humid tropical conditions. Agronomie 24, 383-395 (2004).

40. Todd, R. W., Klocke, N. L., Hergert, G. W. \& Parkhurst, A. M. Evaporation from soil influenced by crop shading, crop residue and wetting regime. Trans. ASAE 34, 461-466 (1991)

41. Thierfelder, C. \& Wall, P. C. Effects of conservation agriculture on soil quality and productivity in contrasting agro-ecological environments of Zimbabwe. Soil Use Manage. 28, 209-220 (2012).

42. Thierfelder, C. et al. How climate-smart is conservation agriculture (CA)? Its potential to deliver on adaptation, mitigation and productivity on smallholder farms in southern Africa. Food Secur. 9, 537-560 (2017).

43. Herrero, M. et al. Smart investments in sustainable food production: revisiting mixed crop-livestock systems. Science 327, 822-825 (2010)

44. Nyamangara, J. et al. Effect of conservation agriculture on maize yield in semi-arid areas of Zimbabwe. Exp. Agric. 50, 159-177 (2014).

45. De Roo, N., Andersson, J. A. \& Krupnik, T. J. On-farm trials for development impact? The organisation of research and the scaling of agricultural technologies. Exp. Agric. 55, 163-184 (2019).

46. Pannell, D. J., Llewellyn, R. S. \& Corbeels, M. The farm-level economics of conservation agriculture for resource-poor farmers. Agric. Ecosyst. Environ. 187, 52-64 (2014).

47. Ngoma, H. Does minimum tillage improve the livelihood outcomes of smallholder farmers in Zambia? Food Secur. 10, 381-396 (2018).

48. Nyagumbo, I., Mkuhlani, S., Mupangwa, W. \& Rodriguez, D. Planting date and yield benefits from conservation agriculture practices across southern Africa. Agric. Syst. 150, 21-33 (2017).

49. Krupnik, T. J. et al. Does size matter? A critical review of meta-analysis in agronomy. Exp. Agric. 55, 200-229 (2019).

50. Harris, D. \& Orr, A. Is rainfed agriculture really a pathway from poverty? Agric. Syst. 123, 84-96 (2014).

51. Van Bruggen, A. H. C. et al. Environmental and health effects of the herbicide glyphosate. Sci. Total Environ. 616-617, 255-268 (2018).

52. Cerdeira, A. L., Gazziero, D. L., Duke, S. O. \& Matallo, M. B. Agricultural impacts of glyphosate-resistant soybean cultivation in South America. J. Agric. Food Chem. 59, 5799-5807 (2011).

53. Kirkegaard, J. A. et al. Sense and nonsense in conservation agriculture: principles, pragmatism and productivity in Australian mixed farming systems. Agric. Ecosyst. Environ. 187, 133-145 (2014).

54. Bai, S. H. \& Ogbourne, S. M. Glyphosate: environmental contamination, toxicity and potential risks to human health via food contamination. Environ. Sci. Pollut. Res. Int. 23, 18988-19001 (2016).

55. Grieser, J., Gommes, R. \& Bernardi, M. New LocClim-the local climate estimator of FAO. Geophys. Res. Abstr. 8, 08305 (2006).

56. Hedges, L. V., Gurevitch, J. \& Curtis, P. S. The meta-analysis of response ratios in experimental ecology. Ecology 80, 1150-1156 (1999).

57. Greenland, S. \& O'Rourke, K. On the bias produced by quality scores in meta-analysis, and a hierarchical view of proposed solutions. Biostatistics 2, 463-471 (2001). 
58. Borenstein, M., Hedges, L. V., Higgins, J. P. \& Rothstein, H. R. A basic introduction to fixed-effect and random-effects models for meta-analysis. Res Synth. Methods 1, 97-111 (2010).

59. Lajeunesse, M. J. On the meta-analysis of response ratios for studies with correlated and multi-group designs. Ecology $\mathbf{9 2}$ 2049-2055 (2011).

60. Duval, S. \& Tweedie, R. Trim and fill: a simple funnel-plot-based method of testing and adjusting for publication bias in meta-analysis. Biometrics 56, 455-463 (2000).

61. Lin, L. \& Chu, H. Quantifying publication bias in meta-analysis. Biometrics 74, 785-794 (2018).

62. Base SAS 9.3 Procedures Guide (SAS Institute, 2011).

\section{Acknowledgements}

This work was implemented as part of the CGIAR Research Programs on Climate Change, Agriculture and Food Security (CCAFS) and Maize, which are carried out with support from the CGIAR Trust Fund and through bilateral funding agreements. The views expressed in this document cannot be taken to reflect the official opinions of these organizations.

\section{Author contributions}

M.C. conceived the project and developed it with A.M.W., R.K and K.N. M.C. and K.N. contributed to the literature research, extracted data from publications and constructed the database. P.L., M.C. and R.K. conducted the analyses. M.C. wrote the manuscript draft and all authors contributed to the interpretation of the results and writing of the final paper.

\section{Competing interests}

The authors declare no competing interests.

\section{Additional information}

Extended data is available for this paper at https://doi.org/10.1038/s43016-020-0114-x. Supplementary information is available for this paper at https://doi.org/10.1038/ s43016-020-0114-x.

Correspondence and requests for materials should be addressed to M.C.

Reprints and permissions information is available at www.nature.com/reprints. Publisher's note Springer Nature remains neutral with regard to jurisdictional claims in published maps and institutional affiliations.

(C) The Author(s), under exclusive licence to Springer Nature Limited 2020 


\begin{tabular}{|c|c|c|c|}
\hline Model fit & & & \\
\hline marginal $r^{2}$ & 0.3 & & \\
\hline conditional $\mathrm{r}^{2}$ & 0.8 & & \\
\hline AIC & -11 & & \\
\hline $\mathrm{n}$ & 933 & & \\
\hline Fixed variables in the model & $\mathrm{df}$ & $F$ & $P$ \\
\hline Crop species & 5 & 4.04 & 0.0016 \\
\hline Crop species x CA level & 13 & 3.85 & $<.0001$ \\
\hline Type of reduced tillage in the CA treatment & 2 & 7.06 & 0.0015 \\
\hline Type of field trial & 1 & 4.49 & 0.0372 \\
\hline Average seasonal rainfall & 3 & 3.86 & 0.0123 \\
\hline Herbicide use in the CA treatment & 2 & 6.22 & 0.0031 \\
\hline Applied chemical phosphorus fertilizer & 3 & 7.62 & $<.0001$ \\
\hline Number of years since the implementation of CA & 1 & 15.55 & 0.0002 \\
\hline Average seasonal rainfall $\mathrm{x}$ soil texture class & 6 & 3.38 & 0.0050 \\
\hline Random variables & Est & & \\
\hline Trial x crop species & 0.0 & & \\
\hline Crop species x CA level x trial & 0.0 & & \\
\hline AR(1) coefficient & 0.5 & & \\
\hline Residuals & 0.0 & & \\
\hline
\end{tabular}

AIC: Akaike information criterion

AR(1): autoregressive model of first order to account for repeated observations over years within one trial

Extended Data Fig. 1 | Random-effects model with explanatory covariates. Results of the random-effects model developed to determine the influence of explanatory covariates on the CA to CT yield ratio. 

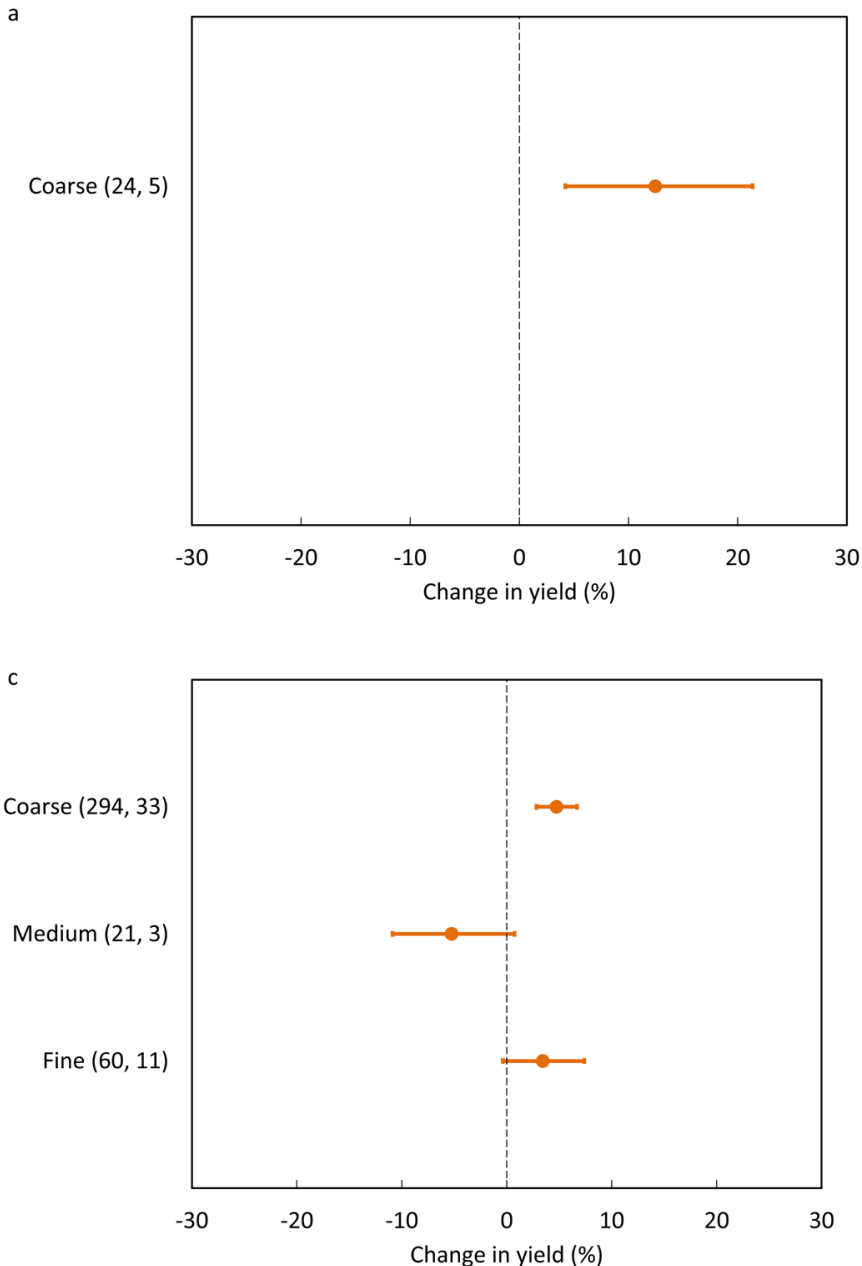

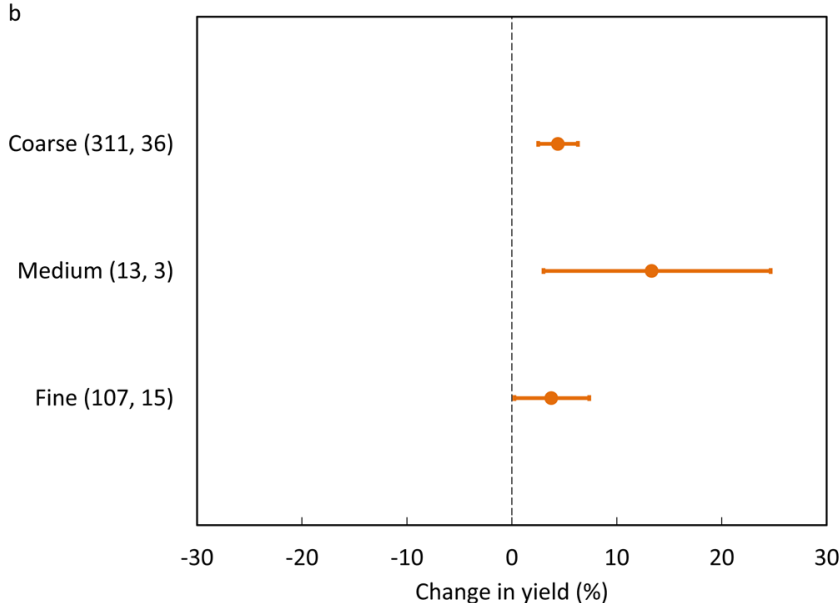

d

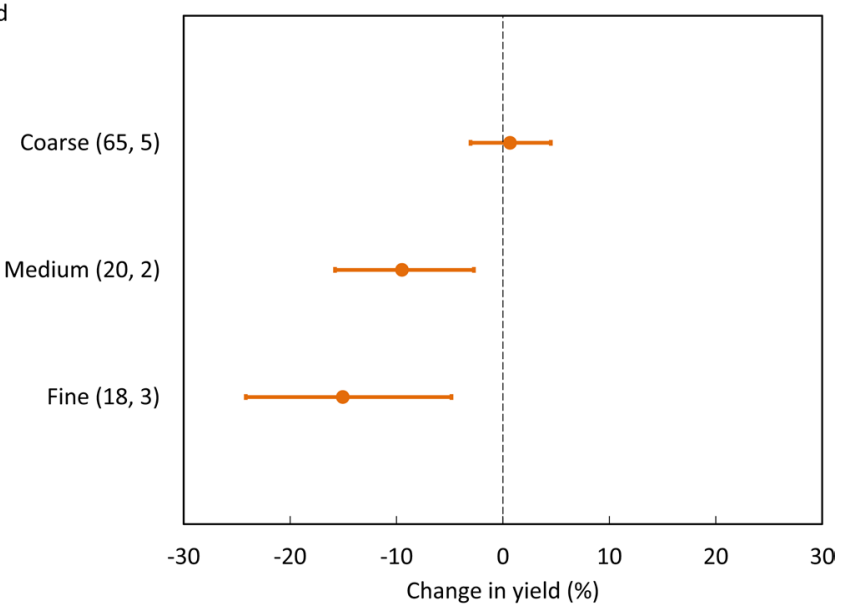

Extended Data Fig. 2 | Effect of CA relative to CT on crop grain yield as a function of soil texture for different regimes of average seasonal rainfall at the experimental site. $\mathbf{a},<400 \mathrm{~mm} ; \mathbf{b}, 400-800 \mathrm{~mm}$; $\mathbf{c}) 800-1200 \mathrm{~m}$ and d) $>1200 \mathrm{~mm}$. Values are mean effect sizes and error bars show the $95 \% \mathrm{Cl}$. The number of observations and total number of studies for each category are shown in parentheses. The mean effect sizes were considered significant if the $95 \% \mathrm{Cl}$ does not include 0 . The $\mathrm{CA}$ effect on yield is significantly lower on medium-texture soils than on coarse- $(P<0.005)$ and fine-textured soils $(P<0.02)$ under the $800-1200 \mathrm{~mm}$ rainfall regime, and the effect on coarse-textured soils is significantly higher than on medium- $(P<0.05)$ and fine-textured soils $(P<0.01)$ under the $>1200 \mathrm{~mm}$ rainfall regime, determined via paired Student's t-tests. 


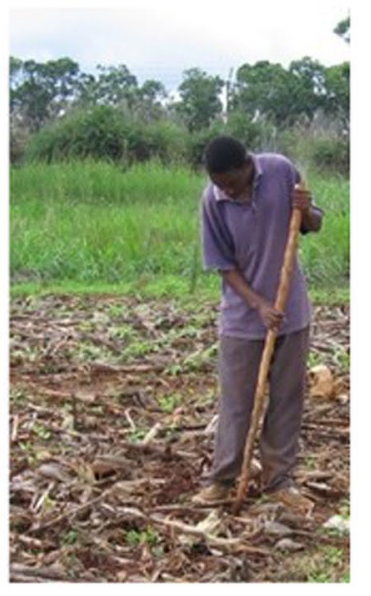

(a) Planting in a hole with a pointed stick

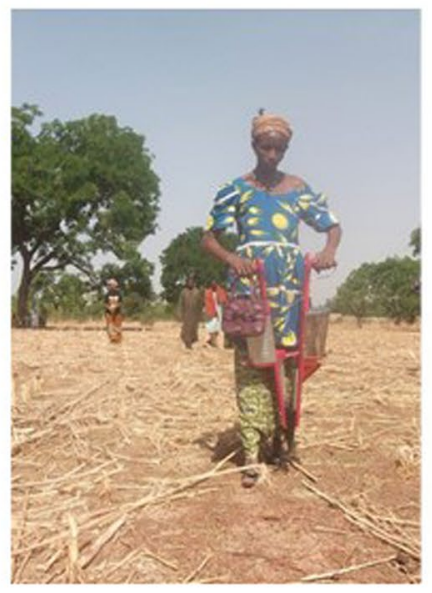

(b) Jab planter

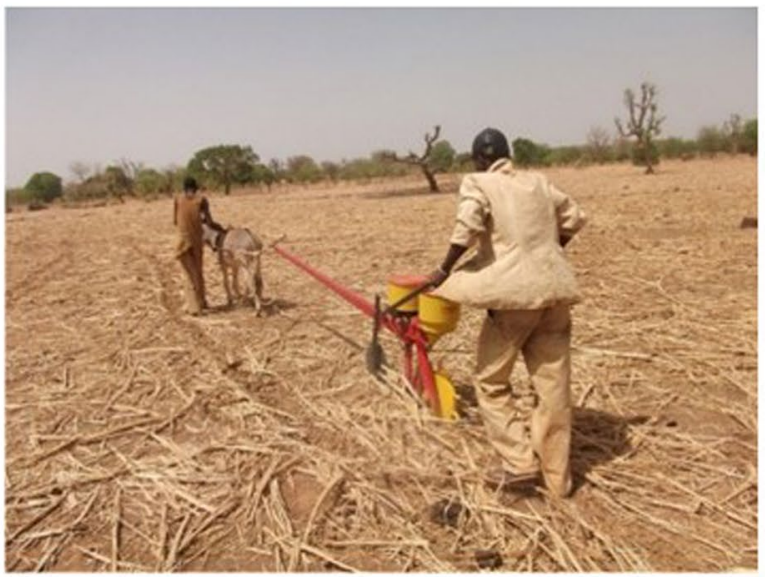

(c) Animal-drawn direct seeder

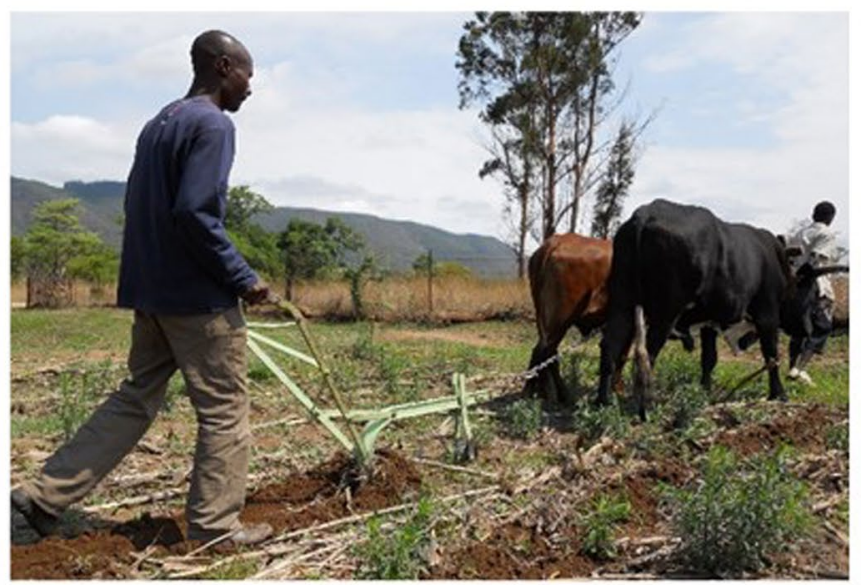

(d) Animal-drawn ripper

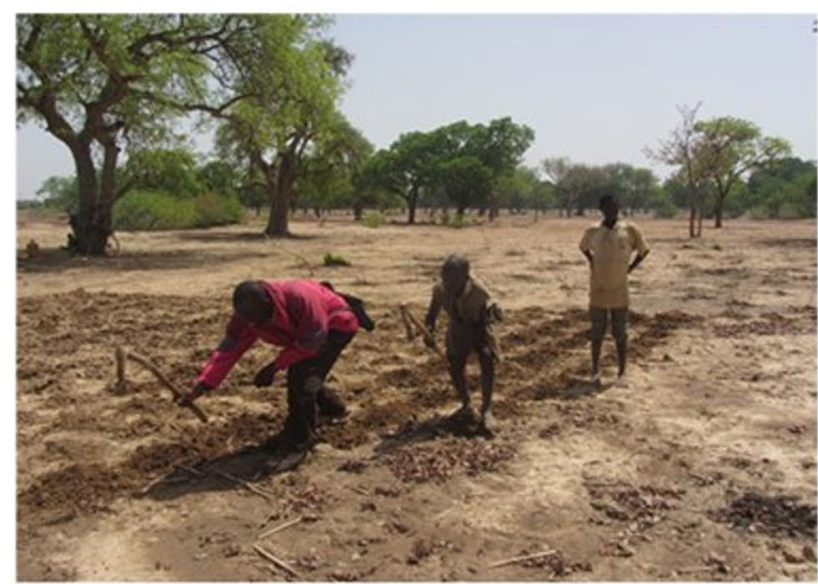

(e) Hand-hoe-made planting basins

Extended Data Fig. 3 | Operational forms of no- and reduced tillage employed by smallholder farmers in sub Saharan Africa. Different operational forms of no- and reduced tillage employed by smallholder farmers in sub Saharan Africa (source: CIRAD and CIMMYT). 
No-tillage $(736,57)$

Minimum tillage $(123,17)$

Basins/permanent beds $(74,7)$

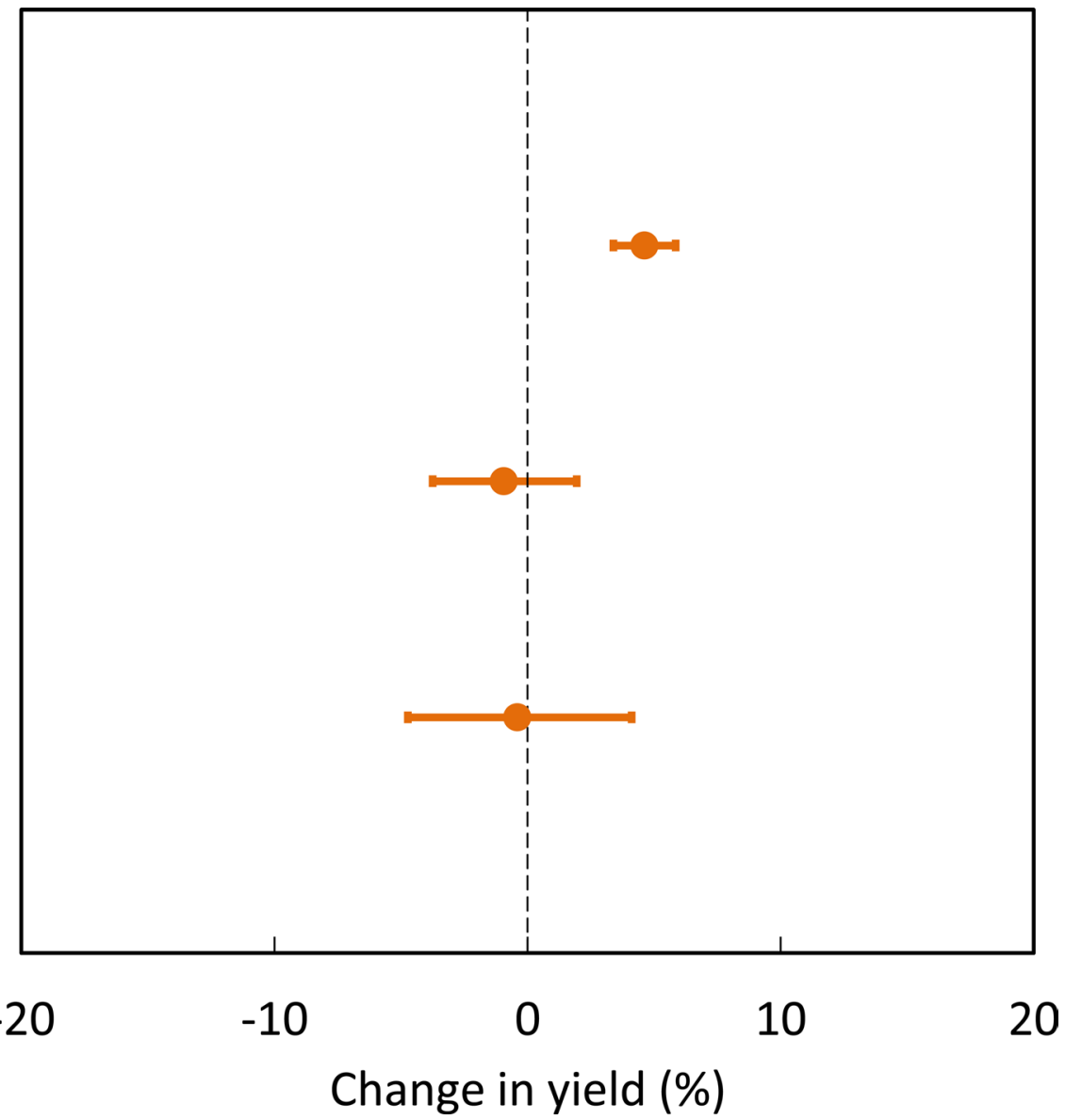

Extended Data Fig. 4 | Effect of CA relative to CT on crop grain yield as a function of type of reduced tillage in the CA treatment. Values are mean effect sizes and error bars show the $95 \% \mathrm{Cl}$. The number of observations and total number of studies for each category are shown in parentheses. The mean effect sizes were considered significant if the $95 \% \mathrm{Cl}$ does not include 0 . The CA effect on yield is significantly higher under no-tillage than under minimum tillage $(P<0.005)$ and basins/permanent beds $(P<0.05)$, determined via paired Student's t-tests. 


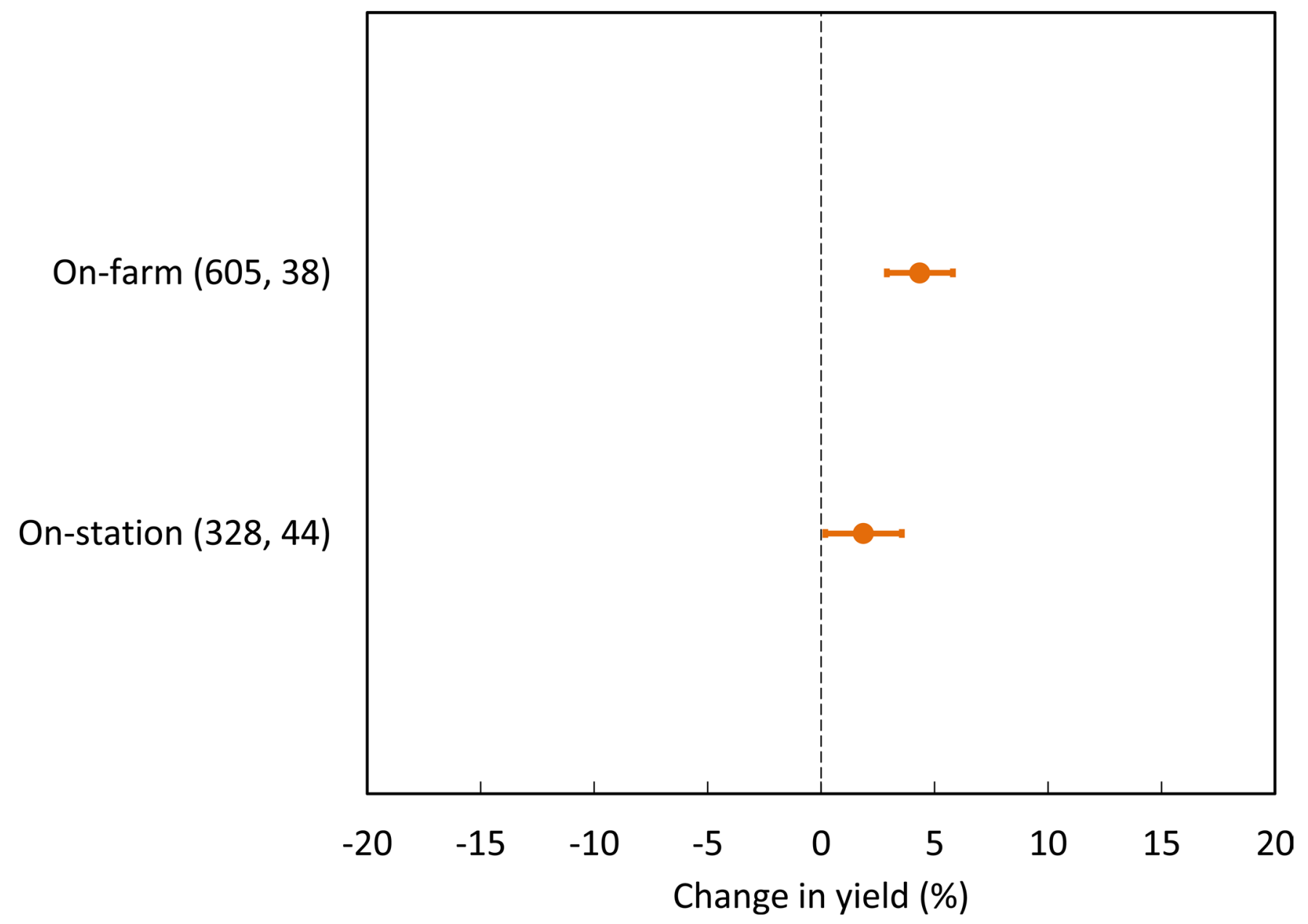

Extended Data Fig. 5 | Effect of CA relative to CT on crop grain yield as a function of type of field trial. Values are mean effect sizes and error bars show the $95 \% \mathrm{Cl}$. The number of observations and total number of studies for each category are shown in parentheses. The mean effect sizes were considered significant if the $95 \% \mathrm{Cl}$ does not include 0 . The CA effect on yield is significantly $(\mathrm{P}<0.05)$ higher in on-farm trials than on-station trials. 


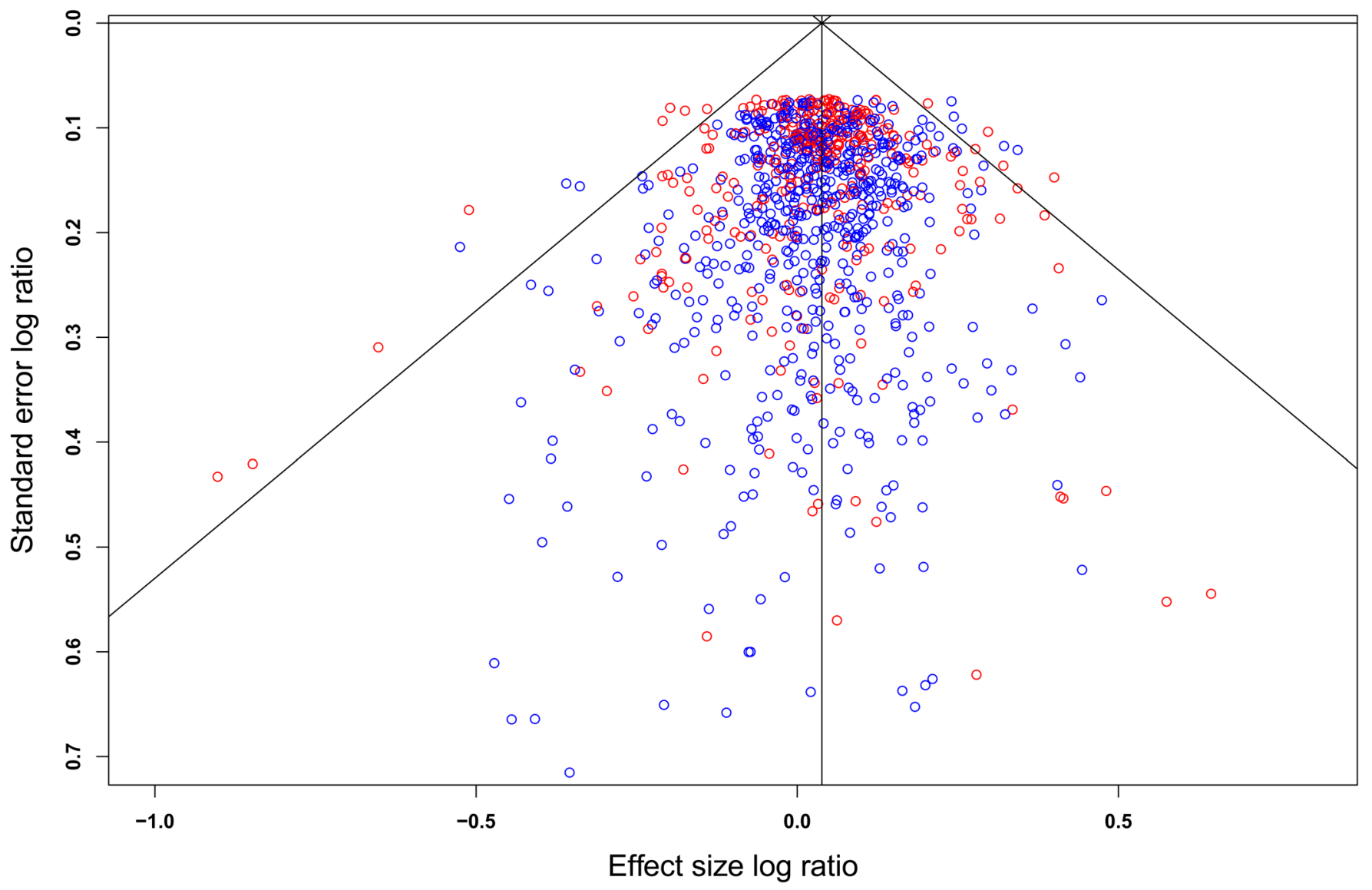

Extended Data Fig. 6 | Funnel plot on the marginal deviations from the random-effects model added to the average logarithmic yield ratio for maize (as reference, solid vertical line). The diagonal lines represent the $95 \% \mathrm{Cl}$ limits around the effect size logratio. Each point represents an observation ( $n=933$ ), open blue circles from on-farm studies $(n=605)$, open red circles from on-station studies $(n=328)$. Skewness TS is -0.03 , $P=0.67$ (all observations), $0.18, \mathrm{P}=0.07$ (on-farm observations) and $-0.26, \mathrm{P}=0.05$ (on-station observations). 


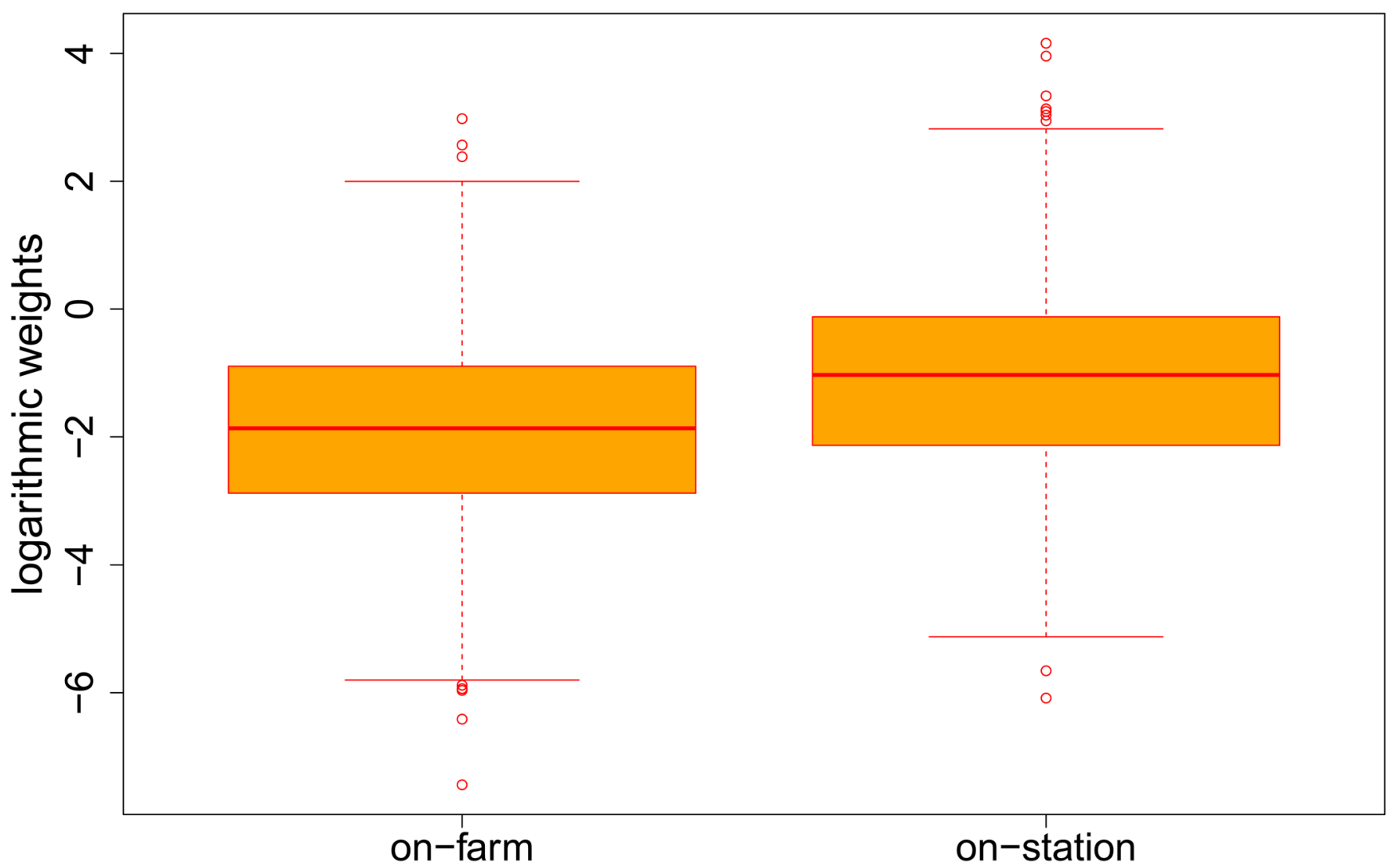

Extended Data Fig. 7 | Boxplots of logarithmic weights by the inverse of variance of the individual observations in the on-farm $(n=605)$ versus on-station $(\mathbf{n}=\mathbf{3 2 8})$ studies. The inverse variance weight is significantly $(P<0.0001)$ smaller in on-farm studies than in on-station studies (paired Student's t-test). 


\section{natureresearch}

Corresponding author(s): NATFOOD-19090321C

Last updated by author(s): Apr 9, 2020

\section{Reporting Summary}

Nature Research wishes to improve the reproducibility of the work that we publish. This form provides structure for consistency and transparency in reporting. For further information on Nature Research policies, see Authors \& Referees and the Editorial Policy Checklist.

\section{Statistics}

For all statistical analyses, confirm that the following items are present in the figure legend, table legend, main text, or Methods section.

n/a Confirmed

$\square$ \ The exact sample size $(n)$ for each experimental group/condition, given as a discrete number and unit of measurement

$\square$ \A statement on whether measurements were taken from distinct samples or whether the same sample was measured repeatedly

The statistical test(s) used AND whether they are one- or two-sided

Only common tests should be described solely by name; describe more complex techniques in the Methods section.

$\square$ \ A description of all covariates tested

$\square$ \A description of any assumptions or corrections, such as tests of normality and adjustment for multiple comparisons

$\square$ A full description of the statistical parameters including central tendency (e.g. means) or other basic estimates (e.g. regression coefficient)

AND variation (e.g. standard deviation) or associated estimates of uncertainty (e.g. confidence intervals)

$\varnothing$ For null hypothesis testing, the test statistic (e.g. $F, t, r$ ) with confidence intervals, effect sizes, degrees of freedom and $P$ value noted

Give $P$ values as exact values whenever suitable.

Х $\square$ For Bayesian analysis, information on the choice of priors and Markov chain Monte Carlo settings

$\square$ \ For hierarchical and complex designs, identification of the appropriate level for tests and full reporting of outcomes

$\square \bigotimes$ Estimates of effect sizes (e.g. Cohen's $d$, Pearson's $r$ ), indicating how they were calculated

Our web collection on statistics for biologists contains articles on many of the points above.

\section{Software and code}

Policy information about availability of computer code

Data collection Data were collected in Microsoft Excel for Office 365 MSO, Version 1904

Data analysis SAS/STAT software, Version 9.3

For manuscripts utilizing custom algorithms or software that are central to the research but not yet described in published literature, software must be made available to editors/reviewers. We strongly encourage code deposition in a community repository (e.g. GitHub). See the Nature Research guidelines for submitting code \& software for further information.

\section{Data}

Policy information about availability of data

All manuscripts must include a data availability statement. This statement should provide the following information, where applicable:

- Accession codes, unique identifiers, or web links for publicly available datasets

- A list of figures that have associated raw data

- A description of any restrictions on data availability

The authors declare that all data analysed during this study are included in this published article and available on-line as a supplementary information file.

\section{Field-specific reporting}

Please select the one below that is the best fit for your research. If you are not sure, read the appropriate sections before making your selection.
Life sciences
$\square$ Behavioural \& social sciences
$\bigotimes$ Ecological, evolutionary \& environmental sciences

For a reference copy of the document with all sections, see nature.com/documents/nr-reporting-summary-flat.pdf 


\section{Ecological, evolutionary \& environmental sciences study design}

All studies must disclose on these points even when the disclosure is negative.

Study description

A meta-analysis of studies in sub-Saharan Africa was conducted comparing crop yields between conservation agriculture and conventional tillage systems.

Research sample

The data set used for the meta-analysis contains 992 observations from 87 published studies that were conducted in 16 different countries in sub-Saharan Africa.

Sampling strategy

The following search terms were used (an asterisk being a replacement for any ending of the respective term): 'conservation agriculture', 'zero till*', 'no till*', 'reduced till*', 'minimum till*', 'direct seeding', or 'direct drill*' in combination with 'yield' and 'Africa' or a country from the list of all countries of SSA (excluding South Africa and Lesotho) in the publication title, abstracts or keywords. The database searches were augmented with hand searches of library resources for relevant papers from citations in retrieved papers.

Data collection

A comprehensive search was conducted using the above search terms for peer-reviewed publications on the effect of CA on crop yields compared to CT in SSA using the online databases ISI Web of Science (Thomson Reuters, New York, NY, USA) and Scopus (Elsevier, Amsterdam, the Netherlands). This was done by the authors of the study.

Studies from the retrieved publications were screened and had to meet the following defined basic selection criteria to be included in the meta-analysis. First, studies report crop yields from field experiments in which a CT treatment is compared with a (partial) CA treatment using statistical methods. Second, at least the effect of no- or minimum tillage is tested with the CA treatment. Third, the experiments are conducted under rainfed field conditions in a specified location in SSA. Fourth, the mean, sample size and standard deviation of crop yields are directly reported as numerical or graphical data or can be calculated from the reported data. Standard deviations were calculated from standard errors, coefficients of variation, $95 \%$ confidence intervals or least significant differences (LSDs), in case that they were not reported in the papers. For some observations, LSD was estimated as the smallest difference between the mean values of treatments that were still significant.

Timing and spatial scale The data are from studies published between 1977 and 2019 - and cover 16 countries of SSA .

Data exclusions

Data from the same study but reported in more than one publication were not repeated to avoid double counting; the publication with the most complete dataset was used. Observations were excluded from the analysis when only average crop yields over several years or sites were presented. If more than one form of tillage was assessed in a study, we selected the CT treatment that represented the greatest soil disturbance. Studies were rejected if crop management practices other than those related to the three CA principles (no- or minimum tillage, residue management or rotation/intercropping) differed between CA and CT treatments, with exception of weed management.

Reproducibility

The selection criteria for studies to be included in the meta-analysis were well defined.

All data analysed during the study are included in the published article and available on-line as a supplementary information file.

Randomization We distinguished three levels of CA in the analysis that represent the varying degrees of application of the CA principles: no- or minimum tillage without mulching and intercropping or rotation (NT-M-IR), no- or minimum tillage with mulching, but without intercropping/rotation (NT+M-IR), and no- or minimum tillage with mulching and intercropping/rotation (NT+M+IR). A list of covariates was tested to explain heterogeneity in study outcomes.

Blinding

During data acquisition from published studies no blinding was undertaken. The selection criteria for studies to be included in the meta-analysis were rigorously followed. Blinding during data analysis by the statistician was done through coding of the studies, observations and treatments.

Did the study involve field work? $\square$ Yes \No

\section{Reporting for specific materials, systems and methods}

We require information from authors about some types of materials, experimental systems and methods used in many studies. Here, indicate whether each material, system or method listed is relevant to your study. If you are not sure if a list item applies to your research, read the appropriate section before selecting a response.

Materials \& experimental systems

\begin{tabular}{l|l}
\hline $\mathrm{n} / \mathrm{a}$ & Involved in the study \\
$\square$ & $\square$ Antibodies \\
$\square$ & $\square$ Eukaryotic cell lines \\
$\square$ & $\square$ Palaeontology \\
$\square$ & $\square$ Animals and other organisms \\
$\square$ & $\square$ Clinical data
\end{tabular}

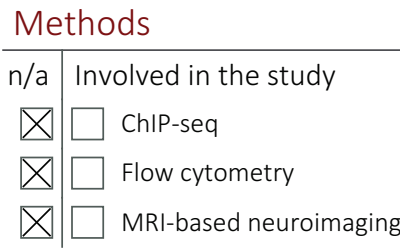

